\title{
"Forecasting stock market prices using mixed ARIMA model: a case study of Indian pharmaceutical companies"
}

\begin{tabular}{|c|c|}
\hline AUTHORS & $\begin{array}{l}\text { Bharat Kumar Meher (D https://orcid.org/0000-0002-7264-5882 } \\
\text { Iqbal Thonse Hawaldar (D) https://orcid.org/0000-0001-7181-2493 } \\
\mathbb{R} \text { https://publons.com/researcher/1456475/iqbal-thonse-hawaldar/ } \\
\text { Cristi Spulbar (D https://orcid.org/0000-0002-3909-9496 } \\
\text { Ramona Birau (D https://orcid.org/0000-0003-1638-4291 }\end{array}$ \\
\hline ARTICLE INFO & $\begin{array}{l}\text { Bharat Kumar Meher, lqbal Thonse Hawaldar, Cristi Spulbar and Ramona Birau } \\
\text { (2021). Forecasting stock market prices using mixed ARIMA model: a case study } \\
\text { of Indian pharmaceutical companies. Investment Management and Financial } \\
\text { Innovations, } 18(1), 42-54 \text {. doi:10.21511/imfi.18(1).2021.04 }\end{array}$ \\
\hline DOI & http://dx.doi.org/10.21511/imfi.18(1).2021.04 \\
\hline RELEASED ON & Friday, 22 January 2021 \\
\hline RECEIVED ON & Wednesday, 11 November 2020 \\
\hline ACCEPTED ON & Monday, 18 January 2021 \\
\hline LICENSE & $\begin{array}{l}(\mathrm{c}) \mathrm{EY} \\
\text { This work is licensed under a Creative Commons Attribution } 4.0 \text { International } \\
\text { License }\end{array}$ \\
\hline JOURNAL & "Investment Management and Financial Innovations" \\
\hline ISSN PRINT & $1810-4967$ \\
\hline ISSN ONLINE & $1812-9358$ \\
\hline PUBLISHER & LLC "Consulting Publishing Company "Business Perspectives" \\
\hline FOUNDER & LLC “Consulting Publishing Company "Business Perspectives" \\
\hline
\end{tabular}

NUMBER OF REFERENCES

18

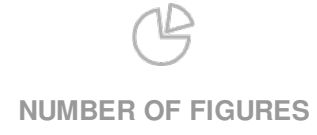

1

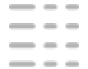

NUMBER OF TABLES

10

(C) The author(s) 2021. This publication is an open access article. 


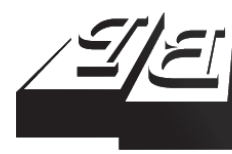

BUSINESS PERSPECTIVES

(O)

LLC "CPC "Business Perspectives" Hryhorii Skovoroda lane, 10, Sumy, 40022, Ukraine www.businessperspectives.org
Received on: $11^{\text {th }}$ of November, 2020 Accepted on: $18^{\text {th }}$ of January, 2021 Published on: 22nd of January, 2021

(C) Bharat Kumar Meher, Iqbal Thonse Hawaldar, Cristi Spulbar, Ramona Birau, 2021

Bharat Kumar Meher, Ph.D., Department of Commerce, D.S. College Under Purnea University, Katihar, Bihar, India.

Iqbal Thonse Hawaldar, Ph.D., Professor, Department of Accounting \& Finance, College of Business Administration, Kingdom University, Bahrain. (Corresponding author)

Cristi Spulbar, Ph.D., Faculty of Economics and Business Administration, University of Craiova, Craiova, Romania.

Ramona Birau, Ph.D., Faculty of Education Science, Law and Public Administration, Constantin Brancusi University of Targu Jiu, Romania.

This is an Open Access article, distributed under the terms of the Creative Commons Attribution 4.0 International license, which permits unrestricted re-use, distribution, and reproduction in any medium, provided the original work is properly cited.

Conflict of interest statement: Author(s) reported no conflict of interest
Bharat Kumar Meher (India), Iqbal Thonse Hawaldar (Bahrain), Cristi Spulbar (Romania), Ramona Birau (Romania)

\section{FORECASTING STOCK MARKET PRICES USING MIXED ARIMA MODEL: A CASE STUDY OF INDIAN PHARMACEUTICAL COMPANIES}

\begin{abstract}
Many investors in order to predict stock prices use various techniques like fundamental analysis and technical analysis and sometimes rely on the discussions provided by various stock market analysts. ARIMA is a part of time-series analysis under prediction algorithms, and this paper attempts to predict the share prices of selected pharmaceutical companies in India, listed under NIFTY100, using the ARIMA model. A sample size of 782 time-series observations from January 1, 2017 to December 31, 2019 for each selected pharmaceutical firm has been considered to frame the ARIMA model. ADF test is used to verify whether the data are stationary or not. For ARIMA model estimation, significant spikes in the correlogram of ACF and PACF have been observed, and many models have been framed taking different AR and MA terms for each selected company. After that, 5 best models have been selected, and necessary inculcation of various AR and MA terms has been made to adjust the models and choose the best adjusted ARIMA model for each firm based on Volatility, adjusted R-squared, and Akaike Information Criterion. The results could be used to analyze the stock prices and their prediction in-depth in future research efforts.
\end{abstract}

Keywords Akaike Information Criterion, augmented Dickey-Fuller test, prediction, risk, investment, India

JEL Classification C22, C53, E27

\section{INTRODUCTION}

The general attitude of the society towards the share market is that it is enormously risky for investment or not suitable for trade. Even though there is the involvement of risk in the stock market, many people are interested in investment. The significant factor for any investor is to maximize the yields on their investments and achieve this element, and the investors always try to predict or forecast the stock prices. Many sound investors use various techniques like fundamental analysis and technical analysis to forecast stock prices. Still, on the other hand, many investors rely on the discussions or suggestions given by various stock market analysts and financial analysts. Some financial analysts and investors use these fundamental or technical analyses and prediction algorithms and functions to predict future share prices and their performance.

The prediction algorithms and functions include time series analysis. The time series analysis is considered an appropriate tool to predict the trend. However, the major limitation of the trend chart is sometimes it might not reflect or predict the variations or steady flow of the market. "The investors are very much interested to know the past trend or flow, seasonal growth, or variations of the stock" (Faisal, 2012; Iqbal \& Mallikarjunappa, 2009). "A general view or expectation is that it must give a holistic view of the stock market. As it is essential to identify a 
model to show the trend with adequate information for the investor to decide." Davi et al. (2013) recommend that "ARIMA is an algorithmic approach to transform the series is better than forecasting directly, and it gives more accurate results." Moreover, Wadia et al. (2011) confirmed that "ARIMA model has a fixed structure and is specifically built for time series (sequential) data." Its forecasts are usually more accurate and reliable as it is a univariate model and hence cannot exploit the leading indicators or explanatory variables.

The study is based on applying the ARIMA model to forecast the share prices of pharmaceutical companies in India. Among all the developing countries, the Indian pharmaceutical industry is one of the biggest and the most sophisticated and plays a pivotal role in the economic development of India. "Being a very intense knowledge-based industry, it offers innumerable business opportunities for investors worldwide. Indian pharmaceutical exports account for export to more than 200 countries around the world" (Kumar et al., 2020). Moreover, as per the report of the Indian Brand Equity Foundation, the low cost of production and increasing research and development has led to competitive pharma exports from exports reached US\$17.15 billion in FY2019. The annual turnover of pharmaceutical products bestows to about US $\$ 20$ billion. The pharmaceutical industry of the country is expected to rise at a CAGR of $22.4 \%$ over $2015-2020$ to reach US\$ 55 billion. The sector was valued at US\$ 33 billion in the previous year. The industry is the third-largest in terms of volume in India. It has been a topmost player in the segment of health care in an epoch of aging populations, increasing health care costs, and the perpetual development of novel and extremely beneficial drugs.

Hence, the investment in securities and shares of pharmaceutical companies appears to be cost-effective. When it comes to the infusion of money in publicly traded pharmaceutical companies, investors should closely examine these companies when they reach clinical trials. Clinical trials are always a make-orbreak chance for firms, and their products - successful outcomes could lead to significant profits in the market. Moreover, "in the recent past, the mutual fund houses aligned their products to invest in the pharma sector. The sector, which has seen a huge decline in the last couple of years, is now a darling for the mutual fund houses. Recently, Mirae Assets and ICICI Prudential announced new thematic schemes keenly focused on maximizing profits from the pharma sector stocks" (Desai, 2018). Hence, this study attempts to frame models to forecast the share prices of selected pharmaceutical companies, which are under NIFTY 100, using a mixed Auto-Regressive Integrated Moving Average (ARIMA).

\section{LITERATURE REVIEW}

There are many kinds of research works in the area of forecasting using time series analysis. Some of the important tasks are mentioned here. A study deals with the implication of support vector machines (SVMs) regression, a novel neural network technique, in predicting the share price to examine the feasibility of SVM regression in predicting stock price. A data set related to Shanghai Stock Exchange in China has been used to test the validity of SVMs regression. The experiment depicts SVMs regression as a valuable method in forecasting the stock price (Bao et al., 2004; Pinto et al., 2020; Kumar et al., 2020). Again, a study focused on forecasting the price of Infosys Technologies, taking into consideration the previous open, close, high, and low price using dif- ferent neural classifier functions like Least Mean Square, Multilayer Perceptron, Pace Regression, Linear Regression, Gaussian Processes, Simple Linear Regression, Isotonic Regression, and SMO Regression (Sureshkumar \& Elango, 2011; Meher et al., 2020). Besides, a study examines the relative predictive power of ARIMA, VAR, and ECM models in predicting inflation in Nigeria. In doing this, a domestic Consumer Price Index (CPI) was lumped into the headline (all-item). Annual data from 1970 to 2010 were used. The study examines the performance of the forecasting ability of the models. It was observed that different models performed well in different periods. While ARIMA is useful as a benchmark model, VAR for short-term forecasting and ECM are suitable for long-run forecasting (Uko \& Nkoro, 2012; Bolar et al., 2017). Furthermore, in a study, the authors reviewed some 
of the approaches, which could be used for a stock market forecast like Hidden Markov Model, Nonlinear Regression Analysis, Naive Bayes Classifier, Artificial Neural Networks, Decision Trees Classifier, Support Vector Machines, Random Forest Method, PCA (Principal Component Analysis), WB-CNN (Word Embeddings Input and Convolutional Neural Network prediction model) and CNN (Convolutional Neural Network) and finally concluded that neural network showed better results compared to other methods (Sharma \& Kaushik, 2018). A study of 10 selected pharmaceutical companies of India, listed in BSE and NSE, was performed with the help of fundamental analysis using the ratio analysis technique (Iqbal \& Mallikarjunappa, 2009, 2010; Panigrahi, Sharma, \& Dhande, 2018). A study considered New York Stock Exchange and NASDAQ Stock Exchange. The research proposed the ARIMA model for ascertaining the value of future share prices. ARIMA revealed better forecasting results as it can handle the time series data very well, which is suitable for forecasting the future share index (Iqbal \& Mallikarjunappa, 2011; Chi \& Subramanian, 2019). Again a study focused on forecasting the gold price in Malaysia with the help of ARIMA with symmetric GARCH-type models if there exists heteroscedasticity (Yaziz et al., 2019). The researches done earlier were not enough to provide an appropriate model to predict the stock prices of pharmaceutical companies of India through ARIMA; hence, this study is an attempt to fill this research gap.

\section{METHODS}

The study is analytical. The data used in this study are from secondary sources. The secondary data involves the daily closing prices of shares of pharmaceutical companies listed in NIFTY 100 of India. The secondary data related to daily closing prices of stocks ranging from January 1, 2017 to December 31, 2019 have been downloaded from Yahoo Finance. Wherever required, an attempt has been made to make the unbalanced data into balanced data, i.e., five days a week. There are nine pharmaceutical companies in India, listed under NIFTY 100, namely Sun Pharmaceutical Industries Ltd., Divi's Laboratories Ltd., Dr. Reddy's Laboratories Ltd., Aurobindo Pharma Ltd., Biocon Ltd., Cadila
Healthcare Ltd., Cipla Ltd., Lupin Ltd., and Piramal Enterprises Ltd. The top three pharmaceutical companies based on market capitalization have been selected for modeling and analysis, i.e., Sun Pharmaceutical Industries Ltd., Lupin Ltd., and Dr. Reddy's Laboratories. The total sample size is 2,346 , i.e., three companies of 782 observations each. A required number of differencing has been done to make the data stationary, and an augmented Dickey-Fuller test has been utilized to check the stationarity of the data. Autoregressive Integrated Moving Average (ARIMA) has been used to formulate the model for each company for the forecasting share price. A correlogram of ACF and PACF would be plotted to determine the different AR and MA terms. After formulating the models, the models have been utilized to predict the share prices from October 1, 2019 to December 31,2019 . The awareness regarding the growth of the pharma industry to the investors is needed. The output of the study could give a potential model for each pharmaceutical company of India selected for this study. Through this study, the share price of selected pharmaceutical companies could be predicted, which could help the scholars and researchers go through proper research to develop best fitted predicted models in the future as well. Moreover, this could also assist investors with a basic knowledge of algorithms to run the developed models to predict the price of selected pharmaceutical companies.

\section{RESULTS AND DISCUSSION}

Auto-Regressive Integrated Moving Average (ARIMA) model is a generalization of an Autoregressive Moving Average (ARMA) model. An ARMA model expresses the conditional mean of $Y_{t}$ as a function of both past observations $Y_{t-1}$, $Y_{t-2}, Y_{t-p}$ and past innovations, $\varepsilon_{t-1}, \varepsilon_{t-q}$. The number of past observations that $Y_{t}$ depends on, $p$, is the AR degree. The number of past innovations that $Y_{t}$ depends on, $q$, is the MA degree.

In general, these models are denoted by ARMA ( $p$, $q)$. The form of the ARMA $(p, q)$ model is

$$
\begin{aligned}
& Y_{t}=\alpha+\beta_{1} Y_{t-1}+\beta_{2} Y_{t-2}+\ldots+\beta_{p} Y_{t-p}+ \\
& +\varepsilon_{t}+\phi_{1} \varepsilon_{t-1}+\phi_{2} \varepsilon_{t-2}+\ldots+\phi_{q} \varepsilon_{t-q},
\end{aligned}
$$


Table 1. The results of the best 5 ARIMA models out of 100 models for Sun Pharmaceutical Industries Ltd.

\begin{tabular}{|c|c|c|c|c|c|}
\hline $\operatorname{ARIMA}(p, d, q)$ & $\begin{array}{c}\text { AIC (Akaike } \\
\text { Information Criterion) }\end{array}$ & $\begin{array}{l}\text { Schwarz } \\
\text { criterion }\end{array}$ & $\begin{array}{l}\text { Volatility } \\
\text { (SIGMASQ) }\end{array}$ & $R$-squared & $\begin{array}{c}\text { Adjusted } \\
R \text {-squared }\end{array}$ \\
\hline $\operatorname{ARIMA}(24,1,47)$ & 7.466761 & 7.49063 & 101.1789 & 0.031146 & 0.027405 \\
\hline $\operatorname{ARIMA}(47,1,24)$ & 7.467272 & 7.491142 & 101.2417 & 0.030544 & 0.026801 \\
\hline $\operatorname{ARIMA}(35,1,47)$ & 7.46908 & 7.49295 & 101.4247 & 0.028792 & 0.025042 \\
\hline $\operatorname{ARIMA}(47,1,131)$ & 7.467994 & 7.491864 & 101.1849 & 0.031088 & 0.027347 \\
\hline $\operatorname{ARIMA}(131,1,47)$ & 7.467841 & 7.491711 & 101.1739 & 0.031193 & 0.027453 \\
\hline
\end{tabular}

where $\alpha$ - constant term, $\beta_{1} \ldots \beta_{p}-\mathrm{AR}-$ non-seasonal autoregressive (AR) coefficients, $\phi$ - MA - Nonseasonal Moving Average (MA) coefficients, $Y_{t-1} \ldots Y_{t-p}-$ non-seasonal AR lags corresponding to non-zero, $\varepsilon_{t-1} \ldots \varepsilon_{t-q}-$ MA lags lags corresponding to non-zero, non-seasonal MA coefficients, $D$ - degree of non-seasonal differencing, $\mathrm{D}$ (if $\mathrm{D}$ has value 0 meaning no non-seasonal integration).

To determine the range of AR and MA degree by examining and comparing the significant spikes in the correlogram of Autocorrelation Function (ACF) and Partial Autocorrelation Function (PACF) of daily closing prices. To determine the five effective ARIMA $(p, d, q)$ model by comparing the models with the help of AIC, adjusted $R$-squared, and significant coefficients were used. To adjust the selected models by inculcating or eliminating more AR and MA terms to develop a best mixed ARIMA model having high $\mathrm{R}$ squared with significant coefficients. The rule of thumb to select better models from the list of developed models with different AR and MA terms is the models with lesser Akaike Information Criterion (AIC), Schwarz criterion, and Volatility, i.e., SIGMASQ, and with higher $R$-squared and adjusted $R$-squared are better. This ARIMA model has been applied in 3 pharmaceutical companies of India, the procedure and results of which are mentioned further.

The closing price of a share of Sun Pharmaceutical Industries Ltd., ranging from January 1, 2017 to December 31, 2019, has been differentiated once to make the data stationary. The closing price data stationarity has been examined with the assistance of a unit root test named augmented DickeyFuller test with the inclusion of the test equation as Intercept, Trend, and Intercept and None. The correlogram of ACF and PACF has been framed by taking $1^{\text {st }}$ difference. By analyzing the correlogram, it has been found that the spikes in ACF and PACF are significant at 3, 9, 13, 15, 17, 18, 24, 35, 47, and 131 lags. Considering these lags, 100 models have been framed by taking different AR and MA terms. These 100 models have been compared, and 5 best models have been selected, the results of which are given in Table 1 . All the models that have been selected have a significant coefficient as the significance values of AR and MA terms are less than 0.05 .

Table 1 represents the best five selected ARIMA models of Sun Pharmaceutical Industries Ltd. It can be observed that in all the selected models, the value of $d$ is 1 , which means that the closing prices have become stationary only by differencing once. By comparing these five best models, the ARIMA $(24,1,47)$ has the least AIC and Schwarz criterion followed by ARIMA $(47,1,24)$ followed by ARIMA $(131,1,47)$. The ARIMA $(131,1,47)$ has the least volatility with the lowest SIGMASQ and has the highest $R$-squared and adjusted $R$-squared. There is also a possibility that some residuals have not been considered in the above models, due to which the $R$-squared and adjusted $R$-squared is still less. Hence, it is necessary to check the residual diagnostic. For this, again, the correlogram of $Q$ statistics has been plotted, and by observing the significant spikes, different AR and MA terms have been inculcated and experimented with adjusting the above five models to achieve higher $R$-squared and adjusted $R$-squared. The results of the best five adjusted ARIMA models are mentioned in Table 2.

Table 2 represents the AIC, Schwarz criterion, Volatility with SIGMASQ, $R$-squared, and adjusted $R$-squared of best five adjusted ARIMA models with different AR and MA terms. The models that have been selected above are having a significant coefficient as the significance value is less than 
Table 2. Results of the best 4 adjusted ARIMA models for Sun Pharmaceutical Industries Ltd.

\begin{tabular}{|c|c|c|c|c|c|}
\hline $\begin{array}{c}\text { ARIMA with different AR } \\
\text { and MA terms }\end{array}$ & $\begin{array}{c}\text { AIC (Akaike Information } \\
\text { Criterion) }\end{array}$ & $\begin{array}{l}\text { Schwarz } \\
\text { criterion }\end{array}$ & $\begin{array}{l}\text { Volatility } \\
\text { (SIGMASQ) }\end{array}$ & $R$-squared & $\begin{array}{r}\text { Adjusted } \\
R \text {-squared }\end{array}$ \\
\hline $\begin{array}{l}\operatorname{AR}(9,18,47,61,79) \\
\operatorname{MA}(13,24,131)\end{array}$ & 7.44407 & 7.503744 & 97.06115 & 0.070576 & 0.059726 \\
\hline $\begin{array}{l}\text { AR }(13,35,47,194) \\
\operatorname{MA}(24,131)\end{array}$ & 7.443417 & 7.491157 & 97.2971 & 0.068316 & 0.059879 \\
\hline $\begin{array}{l}\operatorname{AR}(9,13,24,35,194) \\
\operatorname{MA}(47,131)\end{array}$ & 7.441396 & 7.495103 & 96.86233 & 0.072479 & 0.062868 \\
\hline $\begin{array}{l}\operatorname{AR}(13,24,35,61,131,194) \\
\operatorname{MA}(9,47)\end{array}$ & 7.442778 & 7.502452 & 96.81995 & 0.072885 & 0.062063 \\
\hline
\end{tabular}

0.05. By comparing the values of AIC, Schwarz criterion, and SIGMASQ, it can be said that the ARIMA with AR 9, 13, 24, 35, 194 and MA with 47, 131 terms, has the least AIC, Schwarz criterion, and SIGMASQ. Moreover, the same ARIMA model has the highest $R$-squared and adjusted $R$-squared. Hence, this model would be appropriate for predicting share price. The result of the selected model is mentioned in Table 3.

The mentioned above is the result of the selected model for predicting the share price of Sun Pharmaceuticals. It can be observed that the values of the coefficient are significant, but the $R$ and adjusted $R$-squared are less. With the help of the values of different AR and MA terms and constant term, the following model can be framed:

$$
\begin{aligned}
& D\left(Y_{t}\right)=-0.245651+0.062704 Y_{t-9}+ \\
& +0.088239 Y_{t-13}-0.098491 Y_{t-24}- \\
& -0.090551 Y_{t-35}-0.097406 Y_{t-194}+ \\
& +0.158197 \varepsilon_{t-47}+-0.115884 \varepsilon_{131} .
\end{aligned}
$$

With the help of the above model, the stock prices for the last three months, i.e., October 1, 2019 to December 31, 2019, have been predicted. Then the actual price and the predicted price have been plotted in the forecasting section to check whether the model can predict the price properly or not.

Table 3. Result of the selected model for Sun Pharmaceutical Industries Ltd.

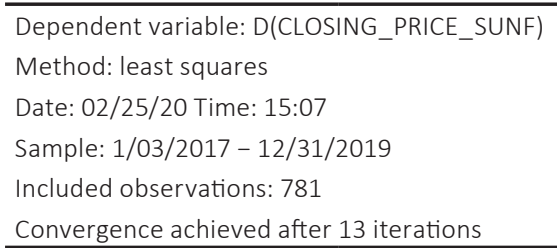

\begin{tabular}{|c|c|c|c|c|}
\hline \multicolumn{5}{|c|}{ Coefficient covariance computed using the outer product of gradients } \\
\hline Variable & Coefficient & Std. Error & t-statistic & Prob. \\
\hline C & -0.245651 & 0.350233 & -0.701393 & 0.4833 \\
\hline$A R(9)$ & 0.062704 & 0.031807 & 1.971361 & 0.0490 \\
\hline$A R(13)$ & 0.088239 & 0.034887 & 2.529319 & 0.0116 \\
\hline$A R(24)$ & -0.098491 & 0.036820 & -2.674966 & 0.0076 \\
\hline$A R(35)$ & -0.090551 & 0.036673 & -2.469141 & 0.0138 \\
\hline$A R(194)$ & -0.097406 & 0.031965 & -3.047220 & 0.0024 \\
\hline$M A(47)$ & 0.158197 & 0.033848 & 4.673810 & 0.0000 \\
\hline$M A(131)$ & -0.115884 & 0.038279 & -3.027322 & 0.0025 \\
\hline SIGMASQ & 96.86233 & 3.116799 & 31.07750 & 0.0000 \\
\hline$R$-squared & 0.072479 & \multicolumn{2}{|c|}{ Mean dependent var } & -0.258003 \\
\hline Adjusted $R$-squared & 0.062868 & \multicolumn{2}{|c|}{ S.D. dependent var } & 10.22572 \\
\hline S.E. of regression & 9.899068 & \multicolumn{2}{|c|}{ Akaike info criterion } & 7.441396 \\
\hline Sum squared resid & 75649.48 & \multicolumn{2}{|c|}{ Schwarz criterion } & 7.495103 \\
\hline Log-likelihood & -2896.865 & \multicolumn{2}{|c|}{ Hannan-Quinn criteria } & 7.462051 \\
\hline F-statistic & 7.540814 & \multicolumn{2}{|c|}{ Durbin-Watson stat } & 1.892796 \\
\hline $\operatorname{Prob}(F$-statistic) & 0.000000 & & & \\
\hline
\end{tabular}


Table 4. Results of the best 5 ARIMA models out of 81 models for Lupin Ltd.

\begin{tabular}{l|c|c|c|c|c}
\hline \multicolumn{1}{c|}{ ARIMA $(\boldsymbol{p}, \boldsymbol{d}, \boldsymbol{q})$} & $\begin{array}{c}\text { AIC (Akaike Information } \\
\text { Criterion) }\end{array}$ & $\begin{array}{c}\text { Schwarz } \\
\text { criterion }\end{array}$ & $\begin{array}{c}\text { Volatility } \\
\text { (SIGMASQ) }\end{array}$ & $\boldsymbol{R}$-squared & $\begin{array}{c}\text { Adjusted } \\
\boldsymbol{R} \text {-squared }\end{array}$ \\
\hline ARIMA $(22,1,98)$ & 8.363473 & 8.387342 & 248.1767 & 0.015311 & 0.011509 \\
ARIMA $(29,1,115)$ & 8.359694 & 8.383564 & 246.9387 & 0.020223 & 0.01644 \\
\hline ARIMA (98, 1, 22) & 8.363273 & 8.387143 & 248.117 & 0.015547 & 0.011746 \\
ARIMA $(102,1,115)$ & 8.361372 & 8.385242 & 247.3055 & 0.018767 & 0.014979 \\
\hline ARIMA $(115,1,102)$ & 8.361278 & 8.385147 & 247.2737 & 0.018893 & 0.015105 \\
\hline
\end{tabular}

Similarly, the closing price of a share of Lupin Ltd., ranging from January 1, 2017 to December 31, 2019, has been differentiated once to make the data stationary. The stationarity of the data has been checked with the help of a unit root test named augmented Dickey-Fuller test with the inclusion of the test equation as Intercept, Trend, and Intercept and None. The correlogram of ACF and PACF has been plotted by taking $1^{\text {st }}$ difference. By analyzing the correlogram, it has been found that the spikes in ACF and PACF are significant at 1,6, $22,24,29,98,102,115$, and 170 lags. By considering these lags, 81 models have been framed by taking different $\mathrm{AR}$ and MA terms. These 81 models have been compared, and 5 best models have been selected, the results of which are given in Table 4.

Table 4 represents the best five selected ARIMA models of Lupin Ltd. It can be observed that in all the selected models, the value of $d$ is 1 , which means that the closing prices have become stationary only by differencing once. By comparing these five best models, the ARIMA $(29,1,115)$ has the least AIC and Schwarz criterion, followed by ARIMA $(115,1,102)$ followed by ARIMA $(102,1$, 115). Again, the model ARIMA $(29,1,115)$ has the least volatility with the lowest SIGMASQ and has the highest $R$-squared and adjusted $R$-squared. Hence, ARIMA $(29,1,115)$ could be considered the best model. However, there is also a possibility that some residuals have not yet been considered in the above models, due to which the $R$-squared and adjusted $R$-squared are still less. Hence, it is necessary to check the residual diagnostic. For this, again, the correlogram of $Q$ statistics has been plotted, and by observing the significant spikes, different $\mathrm{AR}$ and MA terms have been inculcated and experimented with adjusting the above five models to achieve higher $R$ and adjusted $R$-squared. The results of the best five adjusted ARIMA models are mentioned in Table 5.

Table 5 represents the AIC, Schwarz criterion, Volatility with SIGMASQ, $R$-squared, and adjusted $R$-squared of best five adjusted ARIMA models with different AR and MA terms. The models that have been selected above are having a significant coefficient as the significance value is less than 0.05. By comparing the values of AIC, Schwarz criterion, and SIGMASQ, it can be said that the ARIMA with AR 22, 29, 155, and MA with 98, 115 terms has the least AIC, Schwarz criterion, and SIGMASQ. Moreover, the same ARIMA model has the highest $R$-squared and adjusted $R$-squared. Hence, this model would be appropriate for predicting the share price of Lupin Ltd. The result of the selected model is mentioned in Table 6 .

Table 6 mentioned is the result of the selected model for predicting the share price of Sun

Table 5. Results of the best 5 adjusted ARIMA models for Lupin Ltd.

\begin{tabular}{|c|c|c|c|c|c|}
\hline $\begin{array}{c}\text { ARIMA with different AR } \\
\text { and MA terms }\end{array}$ & $\begin{array}{c}\text { AIC (Akaike Information } \\
\text { Criterion) }\end{array}$ & $\begin{array}{l}\text { Schwarz } \\
\text { criterion }\end{array}$ & $\begin{array}{l}\text { Volatility } \\
\text { (SIGMASQ) }\end{array}$ & $R$-squared & $\begin{array}{l}\text { Adjusted } \\
R \text {-squared }\end{array}$ \\
\hline $\begin{array}{l}\operatorname{AR}(1,22,29) \\
\operatorname{MA}(29,98)\end{array}$ & 8.354458 & 8.39623 & 243.7629 & 0.032823 & 0.025326 \\
\hline $\begin{array}{l}\operatorname{AR}(22,29) \\
\operatorname{MA}(98,115)\end{array}$ & 8.350709 & 8.386514 & 243.1943 & 0.035079 & 0.028854 \\
\hline $\begin{array}{l}\operatorname{AR}(22,29,155) \\
\operatorname{MA}(98,115)\end{array}$ & 8.34789 & 8.389662 & 241.5426 & 0.041633 & 0.034204 \\
\hline $\begin{array}{l}\operatorname{AR}(22,29,102) \\
\operatorname{MA}(115)\end{array}$ & 8.352578 & 8.388383 & 243.6976 & 0.033082 & 0.026844 \\
\hline $\begin{array}{l}\operatorname{AR}(29,115) \\
\operatorname{MA}(102)\end{array}$ & 8.357919 & 8.387757 & 245.7358 & 0.024995 & 0.019969 \\
\hline
\end{tabular}


Table 6. Result of the selected model for Lupin Ltd.

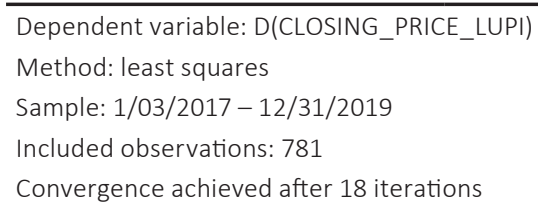

\begin{tabular}{|c|c|c|c|c|}
\hline \multicolumn{5}{|c|}{ Coefficient covariance computed using the outer product of gradients } \\
\hline Variable & Coefficient & Std. Error & $t$-statistic & Prob. \\
\hline C & -0.913487 & 0.496158 & -1.841123 & 0.0660 \\
\hline$A R(22)$ & -0.087667 & 0.041734 & -2.100628 & 0.0360 \\
\hline$A R(29)$ & -0.084947 & 0.040117 & -2.117448 & 0.0345 \\
\hline$A R(155)$ & -0.080189 & 0.034454 & -2.327412 & 0.0202 \\
\hline$M A(98)$ & 0.085273 & 0.043207 & 1.973582 & 0.0488 \\
\hline$M A(115)$ & -0.124606 & 0.043480 & -2.865855 & 0.0043 \\
\hline SIGMASQ & 241.5426 & 6.739731 & 35.83861 & 0.0000 \\
\hline$R$-squared & 0.041633 & \multicolumn{2}{|l|}{ Mean dependent var } & -0.950448 \\
\hline Adjusted $R$-squared & 0.034204 & \multicolumn{2}{|l|}{ S.D. dependent var } & 15.88580 \\
\hline S.E. of regression & 15.61176 & \multicolumn{2}{|l|}{ Akaike info criterion } & 8.347890 \\
\hline Sum squared resid & 188644.7 & \multicolumn{2}{|l|}{ Schwarz criterion } & 8.389662 \\
\hline Log-likelihood & -3252.851 & \multicolumn{2}{|l|}{ Hannan-Quinn criteria } & 8.363955 \\
\hline F-statistic & 5.603931 & \multicolumn{2}{|l|}{ Durbin-Watson stat } & 1.847017 \\
\hline Prob(F-statistic) & 0.000010 & & & \\
\hline
\end{tabular}

Pharmaceuticals. It can be observed that the values of the coefficient are significant, but the $R$ and adjusted $R$-squared are less. With the help of the values of different $A R$ and MA terms and constant term, the following model can be framed:

$$
\begin{aligned}
& D\left(Y_{t}\right)=-0.913487-0.087667 Y_{t-22}- \\
& -0.084947 Y_{t-29}-0.080189 Y_{t-155}+ \\
& +0.085273 \varepsilon_{t-98}-0.124606 \varepsilon_{t-115} .
\end{aligned}
$$

With the help of the above model, the stock prices for the last three months, i.e., from October 1, 2019 to December 31, 2019, have been predicted. Then the actual price and the predicted price have been plotted in the forecasting section to check whether the model can predict the price properly or not.

Similarly, the closing price of a share of Dr. Reddy's Laboratories ranging from January 1, 2017 to December 31, 2019 has been differentiated once to make the data stationary. The stationarity of the data has been checked with the help of a unit root test named augmented Dickey-Fuller test with the inclusion of the test equation as Intercept, Trend, and Intercept and None. The correlogram of ACF and PACF has been plotted by taking $1^{\text {st }}$ difference. By analyzing the correlogram, it has been found that the spikes in ACF and PACF are significant at $6,7,8,24,35,39,53,99,102,144,172$, and 198 lags. Considering these lags, 144 models have been framed by taking different AR and MA terms. These 144 models have been compared, and 5 best models have been selected, the results of which are included in Table 7.

Table 7 represents the best five selected ARIMA models of Dr. Reddy's Laboratories. It can be observed that in all the selected models, the value of $d$ is 1 , which means that the closing prices have become stationary only by differencing once. By

\begin{tabular}{|c|c|c|c|c|c|}
\hline $\operatorname{ARIMA}(p, d, q)$ & $\begin{array}{c}\text { AIC (Akaike Information } \\
\text { Criterion) }\end{array}$ & $\begin{array}{l}\text { Schwarz } \\
\text { criterion }\end{array}$ & $\begin{array}{l}\text { Volatility } \\
\text { (SIGMASQ) }\end{array}$ & $R$-squared & $\begin{array}{c}\text { Adjusted } \\
R \text {-squared }\end{array}$ \\
\hline ARIMA $(24,1,144)$ & 10.25701 & 10.28088 & 1647.706 & 0.019745 & 0.01596 \\
\hline ARIMA $(144,1,99)$ & 10.25876 & 10.28263 & 1648.589 & 0.01922 & 0.015433 \\
\hline $\operatorname{ARIMA}(99,1,144)$ & 10.25817 & 10.28204 & 1647.362 & 0.01995 & 0.016166 \\
\hline $\operatorname{ARIMA}(144,1,24)$ & 10.25732 & 10.28119 & 1648.066 & 0.019531 & 0.015745 \\
\hline ARIMA $(144,1,198)$ & 10.26027 & 10.28414 & 1649.037 & 0.018953 & 0.015166 \\
\hline
\end{tabular}
comparing these five best models, the ARIMA (24,

Table 7. Results of best 5 ARIMA models out of 144 models for Dr. Reddy's Laboratories 
Table 8. Results of best 5 adjusted ARIMA models for Dr. Reddy's Laboratories

\begin{tabular}{|c|c|c|c|c|c|}
\hline $\begin{array}{l}\text { ARIMA with different AR } \\
\text { and MA terms }\end{array}$ & $\begin{array}{c}\text { AIC (Akaike Information } \\
\text { Criterion) }\end{array}$ & $\begin{array}{l}\text { Schwarz } \\
\text { criterion }\end{array}$ & $\begin{array}{l}\text { Volatility } \\
\text { (SIGMASQ) }\end{array}$ & $R$-squared & $\begin{array}{r}\text { Adjusted } \\
R \text {-squared }\end{array}$ \\
\hline $\begin{array}{l}\operatorname{AR}(24,35,151) \\
\operatorname{MA}(39,99,144,151)\end{array}$ & 10.24059 & 10.29429 & 1590.011 & 0.054069 & 0.044267 \\
\hline $\begin{array}{l}\operatorname{AR}(24,35,151) \\
\operatorname{MA}(39,99,144,151,164)\end{array}$ & 10.23557 & 10.29524 & 1572.647 & 0.064399 & 0.053478 \\
\hline $\begin{array}{l}\operatorname{AR}(24,35,144,151) \\
\operatorname{MA}(39,99,151,164)\end{array}$ & 10.23703 & 10.2967 & 1577.854 & 0.061302 & 0.050344 \\
\hline $\begin{array}{l}\text { AR }(24,35,99,144,164) \\
\text { MA }(6,39,198)\end{array}$ & 10.23257 & 10.29224 & 1572.68 & 0.06438 & 0.053458 \\
\hline $\begin{array}{l}\operatorname{AR}(24,35,99,144) \\
\operatorname{MA}(6,39,164,198)\end{array}$ & 10.23227 & 10.29194 & 1571.879 & 0.064856 & 0.05394 \\
\hline
\end{tabular}

$1,144)$ has the least AIC and Schwarz criterion, followed by ARIMA $(144,1,24)$, followed by ARIMA $(99,1,144)$. The ARIMA $(99,1,144)$ has the least volatility with the lowest SIGMASQ and has the highest $R$-squared and adjusted $R$-squared. Again, there is also a possibility that some residuals have not yet been considered in the above models, due to which the $R$-squared and adjusted $R$-squared are still less. Hence, it is necessary to check the residual diagnostic. For this, again, the correlogram of $\mathrm{Q}$ statistics has been plotted, and by observing the significant spikes of ACF and PACF, different $\mathrm{AR}$ and MA terms have been inculcated and experimented with adjusting the above five models to improve $R$ and adjusted $R$-squared. The results of the best five adjusted ARIMA models are mentioned in Table 8.

Table 8 represents the AIC, Schwarz criterion, Volatility with SIGMASQ, $R$-squared and adjusted $R$-squared of best five adjusted ARIMA models with different AR and MA terms. The models that have been selected above are having a significant coefficient as the significance value is less than 0.05. By comparing the values of AIC, Schwarz criterion, and SIGMASQ, it can be said that the ARIMA with AR 24, 35, 99, and 144 and MA with 6, 39, 164, and 198 terms has the least AIC,

Table 9. Result of the selected model for Dr. Reddy's Laboratories

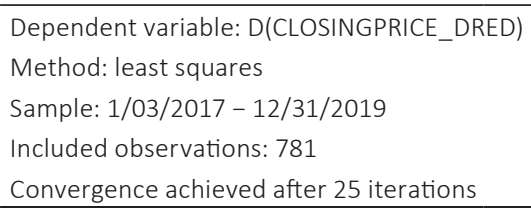

\begin{tabular}{|c|c|c|c|c|}
\hline \multicolumn{5}{|c|}{ Coefficient covariance computed using the outer product of gradients } \\
\hline Variable & Coefficient & Std. Error & t-statistic & Prob. \\
\hline C & -0.430753 & 1.104142 & -0.390124 & 0.6966 \\
\hline$A R(24)$ & -0.090775 & 0.037453 & -2.423679 & 0.0156 \\
\hline$A R(99)$ & -0.083474 & 0.037946 & -2.199784 & 0.0281 \\
\hline$A R(144)$ & -0.080736 & 0.041019 & -1.968265 & 0.0494 \\
\hline$A R(35)$ & -0.083815 & 0.034932 & -2.399393 & 0.0167 \\
\hline MA (198) & 0.110289 & 0.045107 & 2.445059 & 0.0147 \\
\hline$M A(6)$ & -0.079170 & 0.037050 & -2.136841 & 0.0329 \\
\hline MA (39) & -0.087180 & 0.032261 & -2.702299 & 0.0070 \\
\hline$M A(164)$ & 0.100931 & 0.046527 & 2.169284 & 0.0304 \\
\hline SIGMASQ & 1571.879 & 61.16674 & 25.69826 & 0.0000 \\
\hline$R$-squared & 0.064856 & \multicolumn{2}{|l|}{ Mean dependent var } & -0.267413 \\
\hline Adjusted $R$-squared & 0.053940 & \multicolumn{2}{|l|}{ S.D. dependent var } & 41.02500 \\
\hline S.E. of regression & 39.90321 & \multicolumn{2}{|l|}{ Akaike info criterion } & 10.23227 \\
\hline Sum squared resid & 1227637. & \multicolumn{2}{|l|}{ Schwarz criterion } & 10.29194 \\
\hline Log-likelihood & -3985.700 & \multicolumn{2}{|l|}{ Hannan-Quinn criteria } & 10.25522 \\
\hline F-statistic & 5.941368 & \multicolumn{2}{|l|}{ Durbin-Watson stat } & 1.958696 \\
\hline $\operatorname{Prob}(F$-statistic) & 0.000000 & & & \\
\hline
\end{tabular}


Schwarz criterion, and SIGMASQ, moreover, the same ARIMA model has highest $R$-squared and adjusted $R$-squared. Hence, this model would be appropriate for predicting the share price of Dr. Reddy's Laboratories. The result of the selected model is mentioned in Table 9.

It can be observed from Table 9 that the values of the coefficient are significant, but the $\mathrm{R}$ and adjusted R-squared are less. With the help of the values of different AR and MA terms and constant term, the following model can be framed:

$$
\begin{aligned}
& D\left(Y_{t}\right)=-0.430753-0.090775 Y_{t-24}- \\
& -0.083815 Y_{t-35}-0.083474 Y_{t-99}- \\
& -0.080736 Y_{t-144}-0.079170 \varepsilon_{t-6}- \\
& -0.087180 \varepsilon_{t-39}+0.100931 \varepsilon_{t-164}+ \\
& +0.110289 \varepsilon_{t-198} .
\end{aligned}
$$

With the help of the above model, the stock prices for the last three months, i.e., October 1, 2019 to December 31, 2019, have been predicted. Then the actual price and the predicted price
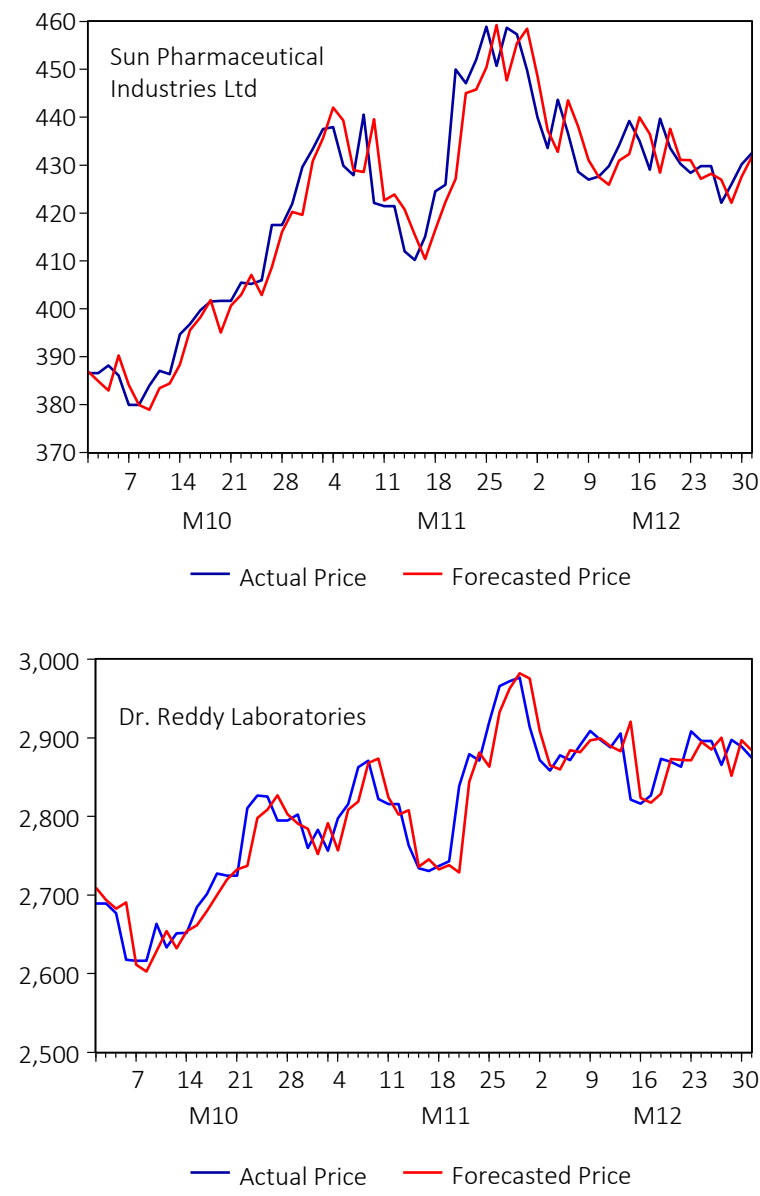

have been plotted in the forecasting section to check whether the model can predict the price properly or not.

Forecasting of stock prices of selected companies

With the help of the above models developed for each selected company under this study, the share prices have been predicted from October 1, 2019 to December 31, 2019. The forecasted prices and the actual prices are represented in the table given in Appendix A.

The values mentioned in that table have been used, and line graphs of Sun Pharmaceutical Industries Ltd., Lupin Ltd., and Dr. Reddy's Laboratories from October 1, 2019 to December 31, 2019 have been plotted, which are mentioned in Figure 1.

The line graphs mentioned in Figure 1 show the actual and predicted price. As the deviations between the actual share price line and predicted share price line are closer, the models can be considered reliable.

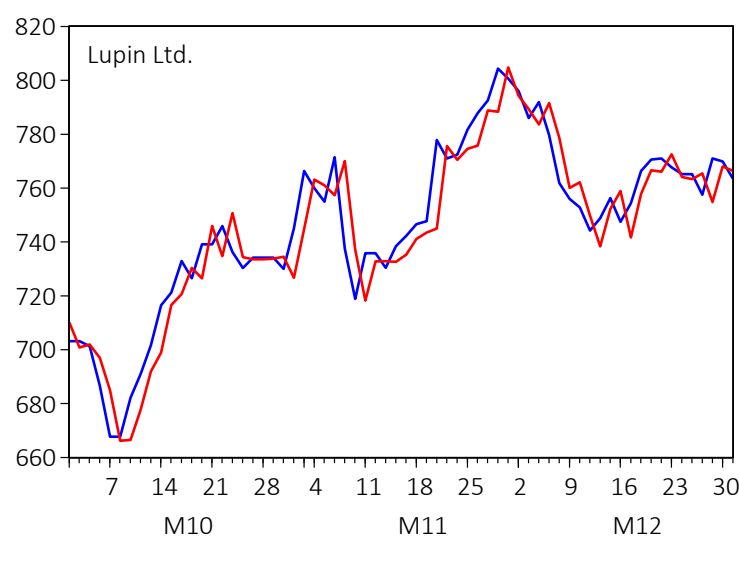

- Actual Price - Forecasted Price

Figure 1. Line graphs of actual and forecasted price from October 1, 2019 to December 31, 2019 


\section{CONCLUSION}

It can be observed that different $\mathrm{AR}$ and MA terms need to be included in the models to make the model more representative. The prediction of share prices of Sun Pharmaceuticals and Lupin Ltd. seems reliable as the deviations between the actual share price and the forecasted share price of the last three months of the study, i.e., from October 1, 2019 to December 31, 2019, is less. However, so far as the predicted share price of Dr. Reddy Laboratories is concerned, slightly more deviations can be found between the actual and predicted share price, which implies that the model developed for Dr. Reddy Laboratories is less reliable to predict the approximate price of the share on a certain date. In the overall study, the models selected for each firm have significant co-efficient, but so far as $R$-squared values are concerned, the values are less than the desired. There is also a possibility of dropping the constant or drift to increase the value of $R$-squared and adjusted $R$-squared to improve the model. The ACF and PACF have been plotted up to 200 lags, i.e., only one-fourth of the total observations. Many more significant lags might be there if the number of lags increased to one-third. Still, if more significant delays would be considered, then it is necessary to formulate and experiment with more models, which are time-consuming and cumbersome processes. Even after the $R$ and adjusted $R$-squared are less in every model, the deviations between the actual values of share and forecasted shares are less, which implies that with the above three mixed ARIMA models, the price can be approximately predicted for the respective companies considered in the study. Moreover, the prices of all pharmaceutical companies are fluctuating. Still, if those prices can be predicted with the help of the models, then investment can be made on pharmaceutical companies of India, and profit can be earned even in the short term. There is also a possibility that the ARIMA models could be formulated by taking fewer periods, which may result in a more reliable model with higher $R$ and adjusted $R$-squared. Formulating mixed ARIMA models by taking different periods and comparing them by observing AIC, Schwarz criterion, Volatility (SIGMASQ), $R$ and adjusted $R$-squared and selecting a best-fitted model is the area for the future study.

\section{AUTHOR CONTRIBUTIONS}

Conceptualization: Bharat Kumar Meher, Iqbal Thonse Hawaldar, Ramona Birau.

Data curation: Bharat Kumar Meher, Cristi Spulbar.

Formal analysis: Iqbal Thonse Hawaldar, Ramona Birau.

Investigation: Bharat Kumar Meher, Ramona Birau.

Methodology: Bharat Kumar Meher, Iqbal Thonse Hawaldar, Cristi Spulbar.

Project administration: Iqbal Thonse Hawaldar.

Validation: Cristi Spulbar, Ramona Birau.

Writing - original draft: Bharat Kumar Meher, Ramona Birau.

Writing - review \& editing: Iqbal Thonse Hawaldar,Cristi Spulbar.

\section{REFERENCES}

1. Bao, Y., Lu, Y., \& Zhang, J. (2004). Forecasting Stock Price by SVMs Regression Yukun. In Lecture Notes in Artificial Intelligence (Subseries of Lecture Notes in Computer Science) (pp. 295-303). https://doi.org/10.1007/978-3540-30106-6_30

2. Bolar, S., Pinto, P., \& Hawaldar, I. T. (2017). Semi-monthly effect in stock returns: new evidence from BombayStock Exchange.
Investment Management and Financial Innovations, 14(3), 160172. http://dx.doi.org/10.21511/ imfi.14(3-1).2017.01

3. Chi, J. L., \& Subramanian, P. (2019). Forecasting of Stock Price Using Autoregressive Integrated Moving Average Model. Journal of Computational and Theoretical Nanoscience, 16(8), 3519-3524. Retrieved from https://www.researchgate.net/
publication/336365885_Forecasting_of_Stock_Price_Using Autoregressive_Integrated_Moving_Average_Model

4. Desai, N. (2018). Pharma sector is the next darling of the market. Retrieved December 5, 2019, from https://www.dsij.in/DSIJArticleDetail/ArtMID/10163/ ArticleID/2458/Pharma-sectoris-the-next-darling-of-market 
5. Devi, B. U., Sundar, D., \& Alli, P. (2013). An Effective Time Series Analysis for Stock Trend Prediction Using ARIMA Model for Nifty Midcap-50. International Journal of Data Mining \& Knowledge Management Process, 3(1), 65-78. https://doi. org/10.5121/ijdkp.2013.3106

6. Faisal, F. (2012). Forecasting Bangladesh's Inflation UsingTime Series ARIMA Models. World Review of Business Research, 2(3), 100-117. Retrieved from https:// studylib.net/doc/12375451/forecasting-bangladesh-s-inflationusing-time-series-arim

7. Iqbal, T. H., \& Mallikarjunappa, T. (2009). Indian Stock Market Reaction to The Quarterly Earnings Information. Indian Journal of Finance, 3(7), 43-50.

8. Iqbal, T. H., \& Mallikarjunappa, T. (2010). A Study of Efficiency of the Indian Stock Market. Indian Journal of Finance, 4(5), 32-38. Retrieved from https://www.researchgate.net/ publication/316239727_A_Study_ of_Efficiency_of_the_Indian Stock_Market

9. Iqbal, T. H., \& Mallikarjunappa, T. (2011). Efficiency of Stock Market: A Study of Stock Price Responses to Earnings Announcements. Germany: LAP Lambert Academic Publishing Company. Retrieved from https://www.researchgate.net/ publication/313599316_Efficiency_of_Stock_Market_A_Study_of_ Stock_Price_Responses_to_Earnings_Announcements

10. Kumar, A., Soni, R., Hawaldar, I. T., Vyas, M., \& Yadav, V. (2020). The Testing of Efficient Market Hypotheses: A Study of Indian Pharmaceutical Industry. International Journal of Economics and Financial Issues, 10(3), 208216. https://doi.org/10.32479/ ijefi.9764

11. Meher, B. K., Hawaldar, I. T., Mohapatra, L., \& Sarea, A. M. (2020). The Impact of COVID-19 on Price Volatility of Crude Oil and Natural Gas Listed on Multi Commodity Exchange of India, International Journal of Energy
Economics and Policy, 10(5), 422431. https://doi.org/10.32479/ ijeep.10047

12. Panigrahi, A. K., Sharma, R., \& Dhande, H. (2018). Fundamental Analysis of Indian Pharmaceutical Companies. Global Management Horizon, 7(1), 2-25. Retrieved from https://papers.ssrn.com/sol3/ papers.cfm?abstract_id=3202129

13. Pinto, P., Hawaldar, I. T., Guruprasad, K., Rohit, B., Spulbar, C., Birau, R., \& Stanciu, C. V. (2020). The Impact of Risk Anomalies on the Pharmaceutical Sector of the Indian Stock Market: A Comparative Analysis between Pharmaceutical, FMCG and IT Companies. Revista de Chimie Journal, 71(2), 58-63. Retrieved from https://www.researchgate. net/publication/339687395_The Impact_of_Risk_Anomalies_on_ the_Pharmaceutical_Sector_of_ the_Indian_Stock_Market_A_ comparative_analysis_between_ pharmaceutical_FMCG_and_IT_ companies

14. Sharma, S., \& Kaushik, B. (2018). Review Article Quantitative Analysis of Stock Market Prediction for Accurate Investment Decisions in Future. Journal of Artificial Intelligence, 11(1), 48-54. https://doi. org/10.3923/jai.2018.48.54

15. Sureshkumar, K. K., \& Elango, N. M. (2011). An Efficient Approach to Forecast Indian Stock Market Price and their Performance Analysis. International Journal of Computer Applications, 34(5), 4449. Retrieved from https://www. semanticscholar.org/paper/AnEfficient-Approach-to-ForecastIndian-Stock-and-Sureshkumar-El ango/5fe8b5c6126aa79fb58637b0d $375 \mathrm{fd} 4 \mathrm{~d} 4 \mathrm{~d} 4 \mathrm{c} 6 \mathrm{a} 6 \mathrm{e}$

16. Uko, A. K., \& Nkoro, E. (2012). Inflation forecasts with ARIMA, vector autoregressive and error correction models in Nigeria. European Journal of Economics, Finance and Administrative Sciences, 50, 71. Retrieved from https://www.researchgate.net/ publication/288453968_Inflation_ forecasts_with_ARIMA_vector_ autoregressive_and_error_correction_models_in_Nigeria
17. Wadia, S. A., Ismail, M. T., Alkhahazaleh, M. H., \& Karim, S. A. (2011). Selecting Wavelet Transforms Model in Forecasting Financial Time Series Data Based on ARIMA Model. Applied Mathematical Sciences, 5(7), 315326. Retrieved December 3, 2019, from http://www.m-hikari.com/ ams/ams-2011/ams-5-8-2011/ alwadiAMS5-8-2011.pdf

18. Yaziz, S. R., Zakaria, R., \& Suhartono. (2019). ARIMA and Symmetric GARCHtype Models in Forecasting Malaysia Gold Price. Journal of Physics: Conference Series, 1. https://doi.org/10.1088/17426596/1366/1/012126 


\section{APPENDIX A}

Table A1. Actual and forecasted prices of Sun Pharmaceutical Industries Ltd., Lupin Ltd. and Dr. Reddy's Laboratories from October 1, 2019 to December 31, 2019

\begin{tabular}{|c|c|c|c|c|c|c|}
\hline \multirow[b]{2}{*}{ MM/DD/YEAR } & \multicolumn{2}{|c|}{ Sun Pharmaceuticals } & \multicolumn{2}{|c|}{ Lupin Ltd. } & \multicolumn{2}{|c|}{ Dr. Reddy Laboratories } \\
\hline & Actual price & $\begin{array}{l}\text { Predicted } \\
\text { price }\end{array}$ & $\begin{array}{l}\text { Actual } \\
\text { price }\end{array}$ & Predicted price & Actual price & $\begin{array}{c}\text { Predicted } \\
\text { price }\end{array}$ \\
\hline 10/01/2019 & 386.549988 & 386.9631 & 703.099976 & 710.0867 & 2689.350098 & 2709.163 \\
\hline $10 / 02 / 2019$ & 386.549988 & 384.9125 & 703.099976 & 700.8380 & 2689.350098 & 2693.781 \\
\hline $10 / 03 / 2019$ & 388.149994 & 382.9368 & 701.200012 & 701.9341 & 2677.149902 & 2682.643 \\
\hline 10/04/2019 & 386.049988 & 390.2636 & 686.5 & 696.9438 & 2617.699951 & 2690.666 \\
\hline $10 / 07 / 2019$ & 379.899994 & 384.0914 & 667.599976 & 684.9523 & 2616.449951 & 2611.236 \\
\hline $10 / 08 / 2019$ & 379.899994 & 379.9513 & 667.599976 & 666.2121 & 2616.449951 & 2602.630 \\
\hline $10 / 09 / 2019$ & 383.950012 & 378.9204 & 682.099976 & 666.5035 & 2663.399902 & 2628.464 \\
\hline $10 / 10 / 2019$ & 387.049988 & 383.4512 & 690.950012 & 677.8391 & 2633.5 & 2654.156 \\
\hline $10 / 11 / 2019$ & 386.299988 & 384.4038 & 701.650024 & 691.9342 & 2651.399902 & 2632.143 \\
\hline $10 / 14 / 2019$ & 394.649994 & 388.3382 & 716.400024 & 698.9567 & 2651.899902 & 2653.852 \\
\hline $10 / 15 / 2019$ & 396.799988 & 395.5917 & 721.150024 & 716.5983 & 2684.649902 & 2661.509 \\
\hline $10 / 16 / 2019$ & 399.700012 & 398.2319 & 732.849976 & 720.6402 & 2701.449951 & 2679.654 \\
\hline $10 / 17 / 2019$ & 401.5 & 401.8214 & 726.5 & 730.3553 & 2727.399902 & 2699.898 \\
\hline 10/18/2019 & 401.649994 & 395.0517 & 739.099976 & 726.5316 & 2724.850098 & 2719.980 \\
\hline $10 / 21 / 2019$ & 401.649994 & 400.6499 & 739.099976 & 745.9349 & 2724.850098 & 2732.732 \\
\hline $10 / 22 / 2019$ & 405.450012 & 402.9271 & 745.849976 & 734.7444 & 2810.75 & 2737.172 \\
\hline $10 / 23 / 2019$ & 405.200012 & 407.1119 & 736.150024 & 750.7402 & 2826.699951 & 2798.125 \\
\hline $10 / 24 / 2019$ & 405.950012 & 402.8990 & 730.25 & 734.3838 & 2825.300049 & 2808.609 \\
\hline $10 / 25 / 2019$ & 417.5 & 408.7538 & 734.099976 & 733.5543 & 2794.949951 & 2826.936 \\
\hline $10 / 28 / 2019$ & 417.5 & 416.0691 & 734.099976 & 733.5585 & 2794.949951 & 2802.685 \\
\hline $10 / 29 / 2019$ & 421.950012 & 420.2553 & 734.150024 & 733.8529 & 2802.5 & 2791.070 \\
\hline 10/30/2019 & 429.649994 & 419.6296 & 729.950012 & 734.5381 & 2759.899902 & 2784.344 \\
\hline $10 / 31 / 2019$ & 433.399994 & 430.8921 & 745.099976 & 726.7670 & 2783.199951 & 2751.992 \\
\hline $11 / 01 / 2019$ & 437.549988 & 435.6230 & 766.299988 & 744.8425 & 2756.600098 & 2791.533 \\
\hline $11 / 04 / 2019$ & 437.950012 & 442.0251 & 759.950012 & 763.2276 & 2797.800049 & 2756.837 \\
\hline $11 / 05 / 2019$ & 429.899994 & 439.3374 & 754.950012 & 761.0847 & 2815.699951 & 2808.621 \\
\hline $11 / 06 / 2019$ & 427.899994 & 428.9682 & 771.450012 & 757.3803 & 2862.699951 & 2819.061 \\
\hline $11 / 07 / 2019$ & 440.600006 & 428.5809 & 737.450012 & 770.0223 & 2871.050049 & 2867.891 \\
\hline $11 / 08 / 2019$ & 422.100006 & 439.6006 & 718.75 & 737.0883 & 2822.100098 & 2873.540 \\
\hline $11 / 11 / 2019$ & 421.450012 & 422.6392 & 735.75 & 718.2671 & 2815.75 & 2824.140 \\
\hline $11 / 12 / 2019$ & 421.450012 & 423.8821 & 735.75 & 732.7605 & 2815.75 & 2802.243 \\
\hline $11 / 13 / 2019$ & 412 & 420.7912 & 730.349976 & 732.8442 & 2763.149902 & 2807.999 \\
\hline $11 / 14 / 2019$ & 410.200012 & 415.4825 & 738.349976 & 732.6323 & 2734.050049 & 2735.976 \\
\hline $11 / 15 / 2019$ & 415.049988 & 410.4001 & 742.25 & 735.3108 & 2730.800049 & 2745.453 \\
\hline $11 / 18 / 2019$ & 424.549988 & 416.5293 & 746.549988 & 741.1748 & 2737 & 2732.606 \\
\hline $11 / 19 / 2019$ & 425.899994 & 422.3090 & 747.700012 & 743.4958 & 2743 & 2738.079 \\
\hline $11 / 20 / 2019$ & 450 & 427.1397 & 777.849976 & 744.9974 & 2838.649902 & 2728.745 \\
\hline $11 / 21 / 2019$ & 447.149994 & 445.0476 & 771 & 775.5906 & 2879.25 & 2844.168 \\
\hline $11 / 22 / 2019$ & 452.100006 & 445.8039 & 772.400024 & 770.5203 & 2871.25 & 2881.208 \\
\hline $11 / 25 / 2019$ & 458.950012 & 450.3957 & 781.700012 & 774.5878 & 2920.649902 & 2863.251 \\
\hline $11 / 26 / 2019$ & 450.75 & 459.2639 & 787.849976 & 775.7867 & 2965.850098 & 2932.737 \\
\hline $11 / 27 / 2019$ & 458.75 & 447.7018 & 792.549988 & 788.8435 & 2972 & 2962.651 \\
\hline $11 / 28 / 2019$ & 457.350006 & 455.4809 & 804.349976 & 788.3817 & 2976.75 & 2982.143 \\
\hline $11 / 29 / 2019$ & 449.850006 & 458.5036 & 800.650024 & 804.8473 & 2913.850098 & 2975.587 \\
\hline $12 / 02 / 2019$ & 440 & 448.5920 & 796.049988 & 794.2559 & 2871.699951 & 2908.763 \\
\hline $12 / 03 / 2019$ & 433.600006 & 437.3284 & 786.049988 & 789.3396 & 2858.350098 & 2864.918 \\
\hline $12 / 04 / 2019$ & 443.700012 & 432.7711 & 791.900024 & 783.6221 & 2877.850098 & 2859.903 \\
\hline $12 / 05 / 2019$ & 436.700012 & 443.5603 & 779.650024 & 791.6104 & 2871.600098 & 2884.277 \\
\hline $12 / 06 / 2019$ & 428.600006 & 438.0687 & 761.849976 & 778.7119 & 2890.800049 & 2881.666 \\
\hline
\end{tabular}


Table A1 (cont.). Actual and forecasted prices of Sun Pharmaceutical Industries Ltd., Lupin Ltd. and Dr. Reddy's Laboratories from October 1, 2019 to December 31, 2019

\begin{tabular}{|c|c|c|c|c|c|c|}
\hline \multirow[b]{2}{*}{ MM/DD/YEAR } & \multicolumn{2}{|c|}{ Sun Pharmaceuticals } & \multicolumn{2}{|c|}{ Lupin Ltd. } & \multicolumn{2}{|c|}{ Dr. Reddy Laboratories } \\
\hline & Actual price & $\begin{array}{l}\text { Predicted } \\
\text { price }\end{array}$ & $\begin{array}{l}\text { Actual } \\
\text { price }\end{array}$ & Predicted price & Actual price & $\begin{array}{l}\text { Predicted } \\
\text { price }\end{array}$ \\
\hline $12 / 09 / 2019$ & 427 & 431.0635 & 755.950012 & 760.1565 & 2908.75 & 2896.728 \\
\hline $12 / 10 / 2019$ & 427.649994 & 427.5426 & 752.799988 & 762.1870 & 2897.5 & 2899.351 \\
\hline $12 / 11 / 2019$ & 429.799988 & 425.9348 & 744.200012 & 749.7892 & 2887.800049 & 2889.428 \\
\hline $12 / 12 / 2019$ & 434.149994 & 430.9636 & 748.75 & 738.4036 & 2905.649902 & 2883.060 \\
\hline $12 / 13 / 2019$ & 439.25 & 432.3350 & 756.25 & 752.2692 & 2821.5 & 2920.722 \\
\hline $12 / 16 / 2019$ & 435.149994 & 440.0159 & 747.450012 & 758.9412 & 2816.350098 & 2823.547 \\
\hline $12 / 17 / 2019$ & 429.049988 & 436.4935 & 754.349976 & 741.7211 & 2826.899902 & 2817.589 \\
\hline $12 / 18 / 2019$ & 439.75 & 428.4282 & 766.349976 & 757.8267 & 2873.449951 & 2828.747 \\
\hline $12 / 19 / 2019$ & 433.600006 & 437.6187 & 770.599976 & 766.6612 & 2869.550049 & 2873.110 \\
\hline $12 / 20 / 2019$ & 430.299988 & 431.1171 & 770.950012 & 766.1206 & 2863.350098 & 2871.974 \\
\hline $12 / 23 / 2019$ & 428.399994 & 431.0725 & 767.700012 & 772.5785 & 2908.399902 & 2871.312 \\
\hline $12 / 24 / 2019$ & 429.799988 & 427.1755 & 765.150024 & 764.1446 & 2895.949951 & 2895.024 \\
\hline $12 / 25 / 2019$ & 429.799988 & 428.2074 & 765.150024 & 763.3488 & 2895.949951 & 2885.271 \\
\hline $12 / 26 / 2019$ & 422.149994 & 426.9992 & 757.5 & 765.4803 & 2865.600098 & 2900.288 \\
\hline $12 / 27 / 2019$ & 426 & 422.1544 & 770.950012 & 754.8204 & 2897.600098 & 2851.648 \\
\hline $12 / 30 / 2019$ & 430.149994 & 427.6038 & 769.900024 & 768.0761 & 2888.850098 & 2897.113 \\
\hline $12 / 31 / 2019$ & 432.549988 & 431.8068 & 763.450012 & 766.4556 & 2874.550049 & 2883.886 \\
\hline
\end{tabular}

